\title{
Mechanical pulping
}

Rita Ferritsius*, Olof Ferritsius, Jan Hill, Anders Karlström and Karin Eriksson

\section{TMP properties and refiner conditions in a CD82 chip refiner at different operation points. Part II: Comparison of the five tests}

https://doi.org/10.1515/npprj-2018-3003

Received September 21, 2016; accepted December 12, 2017; previously published online February 24, 2018 on www.npprj.se

Abstract: This paper is part two of a study on a CD 82 TMP chip refiner where relations between changes in the process conditions and changes in the properties of the produced pulp are investigated. Focus is on the ratio between tensile index and specific energy consumption when results from five tests are compared. Pulp properties were measured for composite pulp samples taken from the refiner blow line. Residence times and pulp consistencies were estimated by use of the extended entropy model. Clearly, an increase in specific energy does not necessarily implicate an increase in strength properties of the pulp produced. It is of high importance to have access to information about the refining zone conditions when searching for an optimal operation point in terms of the ratio between tensile index and specific energy. In these tests, this ratio had a maximum at about $55 \%$ measured blow line consistency. Unfavourable operating conditions were identified at high pulp consistencies, especially after the $\mathrm{FZ}$, where pulp consistencies well above $70 \%$ were observed. The estimated residence time for each refining zone responded differently when applying changes in production rate, plate gaps and dilution water flow rates. In conclusion, the results associated with estimated pulp consistencies where easier to interpret compared with results for residence times, implying that additional tests are required for the latter variable. In addition to tensile index, pulp properties like freeness, Somerville shives and light scattering coefficient were included in the analysis.

\footnotetext{
*Corresponding author: Rita Ferritsius, Mid Sweden University, Sundsvall, Sweden; and StoraEnso Kvarnsveden, Borlänge, Sweden, e-mail: rita.ferritsius@storaenso.com

Olof Ferritsius, Mid Sweden University, Sundsvall, Sweden, e-mail: olof.ferritsius@miun.se

Jan Hill, QualTech AB, Tyringe, Sweden, e-mail: jan.hill@qtab.se Anders Karlström, Chalmers University of Technology, Gothenburg, Sweden, e-mail: anderska@chalmers.se

Karin Eriksson, CIT Industriell Energi, Gothenburg, Sweden
}

Keywords: CD 82 refiner; entropy model; fibre properties; handsheet properties; plate gap; pulp quality; residence time; specific energy; temperature measurements; TMP refiners.

\section{Introduction}

CD refiners were introduced in the late seventies. Tistad et al. (1981) reported on mill results from the first installation, and Ferritsius et al. (1989) compared the CD pulp properties to the results achieved by double disc refining (DD). Strand et al. (1993) studied the impact of production rate and refiner RPM on energy efficiency at selected pulp property targets. Johansson et al. (2001) and Johansson and Richardson (2005) applied temperature sensor arrays to support optimization of the CD-refiner in respect to energy efficiency. Deer et al. (2005), Fostokjian et al. (2005) and Bussiere et al. (2007) addressed the influence of segment patterns on energy needed to develop required pulp properties. Although different in focus and methods, these studies have in common that they all state that a potential for reduced energy consumption at maintained pulp properties is possible.

During the last two decades, there have been developments in pulp sampling procedures and testing, as well as in refining zone measurement techniques and modelling of refining processes. These are prerequisites for a more detailed analysis compared with those presented in earlier studies. Backlund (2004) studied shear forces, temperature profiles and fibre development. In addition, the CD82 refiner was equipped with a pulp sampling gate after the flat zone. Backlund applied multivariate data analysis to relate the measured consistency, freeness, Bauer McNett long fibre fraction and shives content to gap and dilution flow rate of the flat and conical zones respectively.

Characterization of operating conditions in a refining process is not straightforward. Other studies have shown that different combinations of dilution water flows and 
plate gap can result in the same level of refiner motor load, see for example Johansson et al. (1980), Hill (1993) and Hill et al. (1993). This indicates that other variables must be considered when describing the process conditions. Miles and May (1989) argued that the most important process variable is pulp consistency, which determines the pulp properties that can be achieved at a specific energy consumption.

Härkönen and Tienvieri (1999) conducted a study where a radioactive tracer was injected in a SD 65 refiner. Based on the results they argued that fibre residence time is one of the most important variables of the refining process. A similar approach was applied by Vikman et al. (2005) when studying residence time in CD 82 refiners. These two studies show that determining values of residence time from experiments is a complex task. If values of this variable is to be obtained at a satisfying frequency, model-based estimations are needed. Karlström and Eriksson (2014) addressed this by modelling the conditions in the refining zone by formulating the extended entropy model. The model is used to compute physical conditions in the refining zone e.g. consistency and fibre residence time as a function of radius.

This paper is the third in a series that explores refiner variables and pulp quality. The first explored variation in refiner conditions and pulp quality during normal running (Ferritsius et al. 2017). The second paper studied three of the tests in more detail (Ferritsius et al. 2018). This paper compares the different tests. The refiner conditions both measured and estimated have been related to changes in the properties of the produced pulp. Specifically, the ratio between tensile index and specific energy consumption is in focus. Data from five tests with a CD 82 refiner is considered. These tests were performed in the Filling the gap project (Engstrand and Engberg 2014), but have now been analysed further using internal variables that have been calculated using the extended entropy model presented by Karlström and Eriksson (2014, part I). Pulp properties were measured for composite pulp samples taken during $3 \mathrm{~min}$ from the refiner blow line. Residence times and pulp consistencies were estimated using the extended entropy model. These variables relate to conditions inside the refining zone and are referred to as internal variables (Karlström and Isaksson 2009). Production rate, plate gap and motor load are measured near but not inside the refining zone and such variables are referred to as external variables. Different model approaches have been further explored from a dynamical process and pulp property perspective by Karlström et al. (2015, 2016a, 2016b).

In Ferritsius et al. (2018) results from individual tests are presented. The purpose of this paper is to: i. Compare the results from the different tests and identify process conditions for this refiner where the specific energy is low while certain values in tensile index and fibre length are obtained

ii. Evaluate if internal variables such as residence times and consistencies can offer additional information that can explain the obtained differences in pulp properties

\section{Materials and methods}

The study of the conical disc (CD) refiner was performed in three parts. The first part aimed to evaluate variation of the refiner conditions and pulp quality during normal operation. During this first test (TEST1), sample time was evaluated for composite pulp samples collected during 3 and $1 \mathrm{~min}$, respectively (Ferritsius et al. 2018). This study showed that a sample time of 3 min could be recommended. The data from the 3-min sampling made in TEST1 has been included in this paper where all tests are compared. The tests where refiner conditions were changed have been presented separately, with the exception of TEST3 (Ferritsius et al. 2018). Operational problems were encountered during TEST3, and therefore, this test was not included in the detailed study of the test in Ferritsius et al. (2018). However, in this paper all tests have been included for comparison. In addition, this material has also been used by Karlström et al. (Part I-III, 2015, 2016a, 2016b).

The study presented considers a full-scale production line with a CD 82 refiner as chip refiner followed by a LC refiner (CF 82) in the main line. After the main line, the pulp is screened and reject refined for final use for newsprint. The raw material was Norway spruce (Picea abies). The CD 82 refiner was running at $1800 \mathrm{rpm}$ and is equipped with a $25 \mathrm{MW}$ motor. The refiner has two serially linked refining zones called the flat zone (FZ) and the conical zone (CZ). In both zones, temperature sensor arrays were mounted for measurement of temperature profiles. For further details see Engstrand and Engberg (2014) and Ferritsius et al. (2014). The temperature measurements have been used together with plate gap measurements, information about the specific refiner (such as plate pattern and taper) and additional process variables (such as dilution water and motor load), to derive estimates of consistency and residence time by the extended entropy model described by Karlström and Eriksson (2014, Part I). When it comes to the $\mathrm{CD}$ refiner, residence time and consistency estimates can be derived for both the FZ and the $\mathrm{CZ}$, and values of these variables are considered in the analysis that follows. 
With this set-up, a total of five tests were conducted during a period of three months covering a large operating window. During all tests, pulp samples were collected in the blow line of the CD 82 refiner. A careful sampling procedure is vital, and Ferritsius et al. (2018) showed that this involves composite pulp samples collected as approximately 30 part samples during a three-minute period. The composite pulp samples were homogenized carefully and 3-5 pulp consistencies were measured. Next, the pulp samples were packed in $55 \mathrm{~g}$-packages and stored in a freezer before further testing.

The five tests were conducted with different purposes: TEST1 involved continuous operation at one single operating point. This test involved a total of 20 composite pulp samples allowing studying procedures for pulp sampling and subsequent testing presented by Ferritsius et al. (2018). During this test, both 1 and 3-min sampling times were tested. In this paper, only 3-min data is included.

TEST2 investigated the refining conditions in the FZ by applying step-changes in the associated dilution water flow and plate gap. This test covered nine composite pulp samples.

TEST3 aimed at investigating the refining conditions in the $\mathrm{CD}$ zone (CZ) by step-changes in the associated dilution water flow and plate gap. However, operational problems occurred during this test; a reduced number of just four composite pulp samples were obtained and thereby, the potential to analyse this test was limited.

TEST4 targeted influence of production rate changes by testing three major levels in the range 12.5 to $15.9 \mathrm{admt} / \mathrm{h}$. In total, this test series comprised $15 \mathrm{com}$ posite pulp samples.

TEST5 further investigated change in amount of dilution water by applying changes in the flows to both the FZ and the CZ. In total, this series comprised 15 pulp samples.

In Table 1, numerical values of some selected process variables are given. Production rate was determined based on measuring flow rate and consistency out from the latency chest placed after the refiner. During the tests, no changes in set-point for the latency chest level were applied. During all tests, process variables were measured at $4 \mathrm{~Hz}$.

The pulp samples were hot disintegrated according to ISO 5263-3:2004 before further testing. Freeness was measured according to ISO 5267-2:2001. Fibre length was measured according to ISO 16065-2:2007 using FiberLab. FiberLab measurements were made three times and averages of these are reported in this paper. Somerville shives were measured according to Tappi 275 sp-98. Handsheets without recirculation of white water were made according to ISO 5269-1:2005. The handsheet density was measured according to ISO 534:2011. Tensile index was measured on the handsheets according to ISO 1924-3:2005.

For tensile index values, the number of handsheets was increased compared to the ISO standard and 20 strips where used instead of 8. Duplicate testing was used resulting in tensile index values based on 40 strips. Light scattering was measured according to ISO 9416:2009.

\section{Results}

\section{Process variables and pulp consistency}

The five tests were carried out over a three-month period. The effective time of performing all tests was about $24 \mathrm{~h}$. Figure 1 shows refiner motor load and pulp consistency during these 24 hours. Measured values of blowline pulp consistency are shown together with consistency estimated by the extended entropy model. During each 3-min period when composite pulp samples were taken, the motor load variations were about $+/-1.5-2.5 \mathrm{MW}$. The process variables were measured at $4 \mathrm{~Hz}$. In part of TEST1, 1-minute pulp sampling periods were used, to enable comparison between 3- and 1-min procedures, see Ferritsius et al. (2018). For all remaining composite pulp samples in the test, 3-min pulp sampling periods were used.

Table 1: Mean values of plate gaps, dilution water feed rates and production rate during the tests.

\begin{tabular}{lrrrrr}
\hline & TEST 1 & TEST 2 & TEST 3 & TEST 4 & TEST 5 \\
\hline Prod, admt/h & 13.4 & 15.9 & 15.0 & $12.5-15.9$ & 14.2 \\
Dil. FZ, l/s & 3.26 & $3.17-3.42$ & 3.79 & 3.40 & $3.28-3.51$ \\
Dil. CZ, l/s & 4.76 & 5.23 & $5.06-5.12$ & 3.88 & $4.44-4.70$ \\
Gap FZ, mm & 1.53 & $1.05-1.36$ & 1.24 & 1.48 & 0.86 \\
Gap CZ, mm & 0.86 & 0.78 & $0.57-0.64$ & 1.14 & 0.65 \\
\hline
\end{tabular}



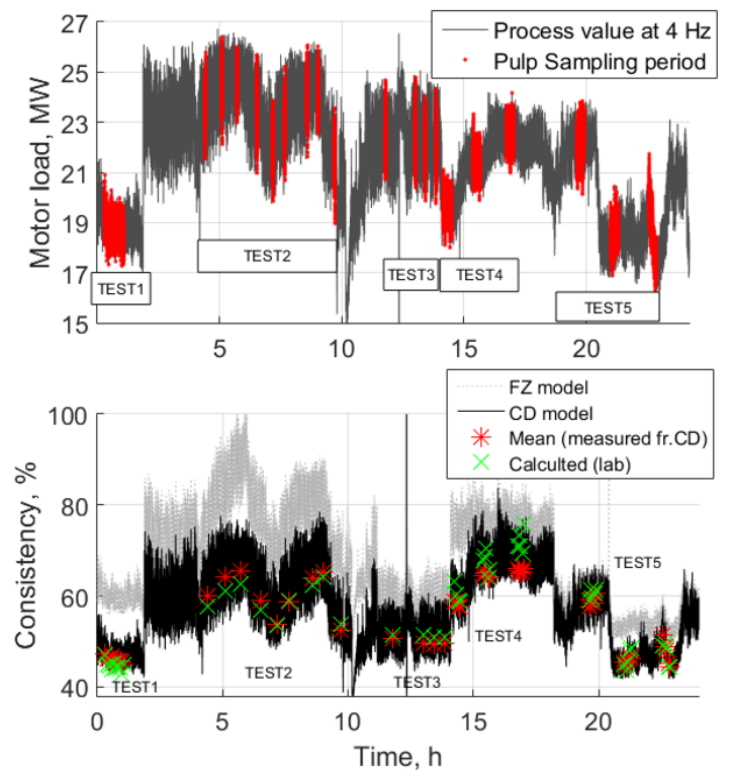

Figure 1: Top: The refiner motor load during all five tests. Red marks periods when composite pulp samples were taken. Bottom: Estimated and measured pulp consistency during all five tests. Estimated pulp consistency is shown both after FZ (grey) and CD zone (black).

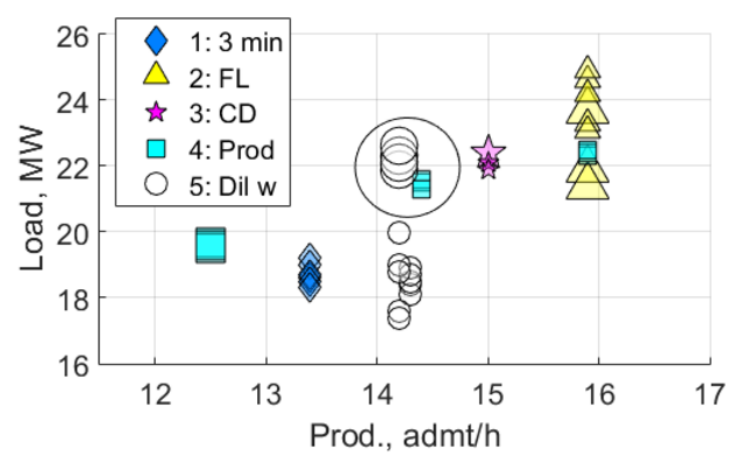

Figure 2: A large operating window was covered by the five tests, here illustrated by the variables Production rate and Motor load. The circle indicates pulp sampling periods with similar values in both motor load and production rate.

Together, the tests covered a large operating window considering production rate and average motor load, see Figure 2. All of the five tests started at the prevailing operating point, meaning that the operating conditions at each of the five starting points can be classified as representative during continuous operation. In Figure 2, larger symbols are used to represent the starting points for each individual test. For all tests, the specific energy range was 1200 to $1600 \mathrm{kWh} /$ admt (see Table 3-7 in the appendix). Moreover, in Figure 2, a circle is placed around markers re-
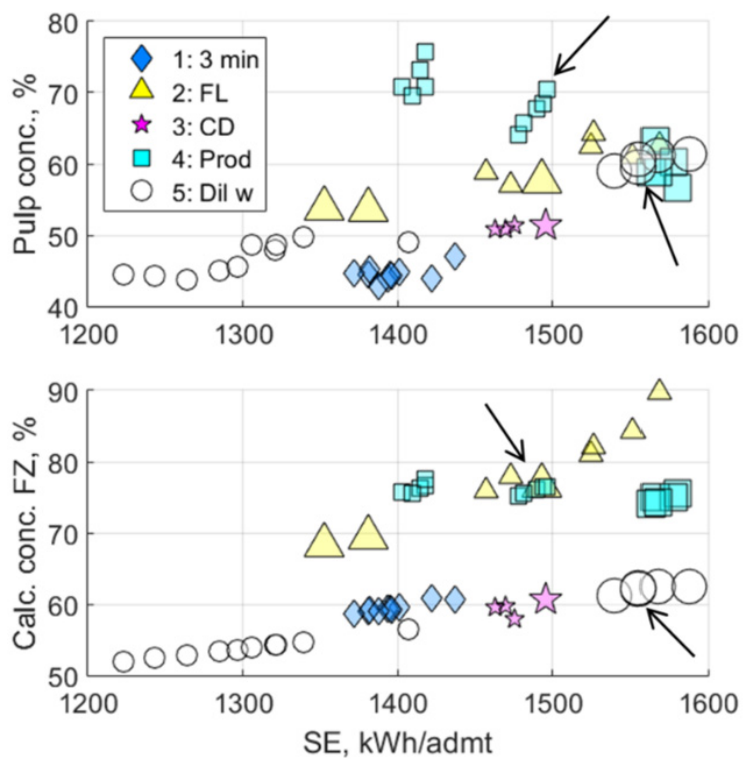

Figure 3: Measured pulp consistency in the blow line (after the CD zone) and estimated pulp consistency after $F Z$, both versus specific energy. The arrows indicate pulp sampling periods with similar values in both motor load and production rate.

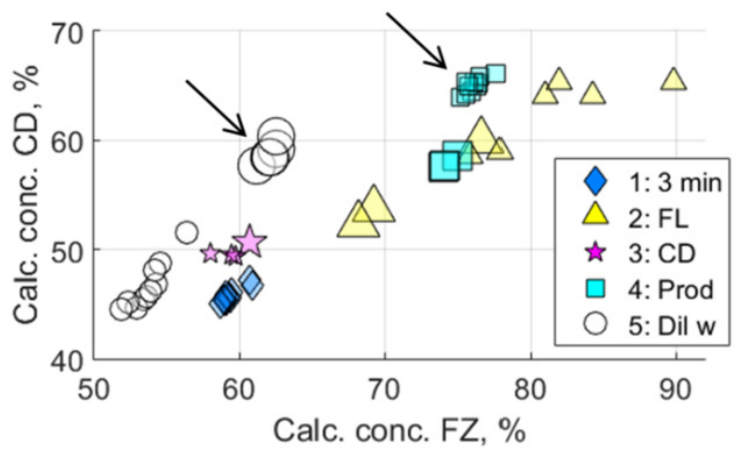

Figure 4: The operating window for estimated consistency after the $F Z$ and after the $C D$ zone that was covered by the five tests. The arrows indicate pulp sampling periods with similar values in both motor load and production rate.

ferring to pulp sampling periods having similar values in both motor load and production rate. Later, in the result section, these will be discussed in more detail.

In individual tests, set-point changes were applied in production rate, plate gaps and dilution water flow rates, with the exception of TEST1, where no changes were applied (see Table 3-7 in the appendix for further details). The changes made in these process variables influenced the pulp consistency after both the FZ and the CD zone. In relation to specific energy, the magnitude of the response in consistency could differ between the two locations, see Figure 3 and 4. 
During TEST2 and 5, the pulp consistency increased with increased specific energy as shown in Figure 3. With respect to specific energy, the values of the measured blow line consistency were in the same range during these two tests. The estimated consistency after the FZ was, however, higher during TEST2 compared with TEST5, as shown in Figure 4. Comparing all tests, the lowest values of consistency after the FZ were obtained during parts of TEST5. In TEST4, where changes in production rate were made, the measured blow line consistency clearly decreased with increased specific energy. The effect on the estimated consistency after the FZ was not as pronounced.

The extended entropy model was used to estimate the total fibre residence time. In Figure 5, the obtained mean values for the periods of composite pulp sampling are shown with respect to specific energy. Within each test, it can be seen that the total residence time increases with increased specific energy. TEST3 is an exception, but taking into account the operational difficulties experienced during this test, conclusions cannot be drawn from this test alone.

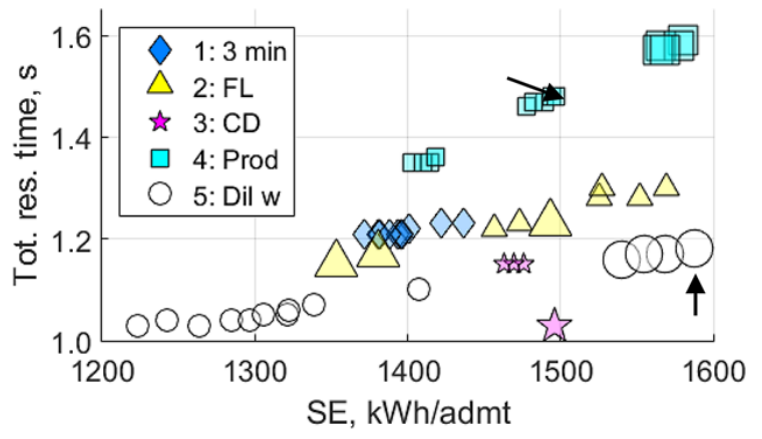

Figure 5: Estimated residence time versus specific energy. The arrows indicate pulp sampling periods with similar values in both motor load and production rate.

If considering all pulp sampling periods during all five tests, there is no clear relation between the total residence time and the specific energy. For a certain level of specific energy, a fairly wide range in total residence time can be obtained. To some extent, this is related to the production rate, see the difference in production level in Figure 2, but differences in this variable is not the only cause, as shown for the samples marked with arrows in Figure 5, which had a similar production level.

During TEST4, the specific energy decreased when the production rate increased. This could perhaps explain the steeper change in estimated residence time obtained for this test compared with remaining tests. While a positive correlation was observed between the total residence time and the specific energy in TEST4, the correlation between total residence time and pulp consistency was negative, Figure 6.

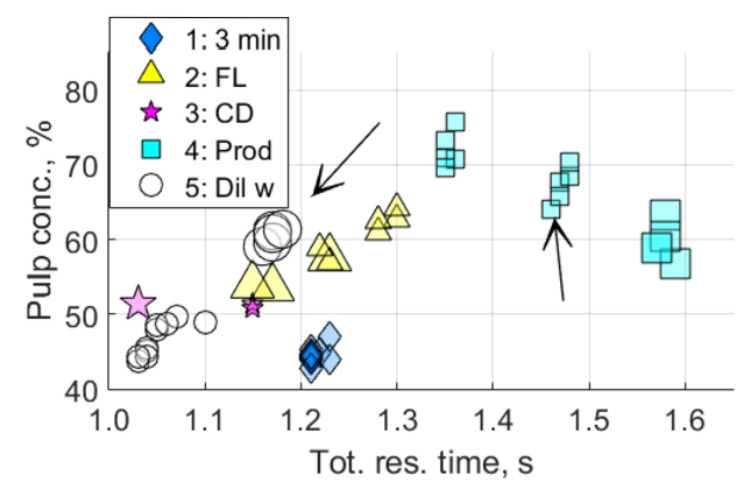

Figure 6: For TEST4, a negative correlation between measured pulp consistency and estimated total residence time was obtained. For remaining tests, the relation found was rather the opposite. The arrows indicate operating points that had similar values in both motor load and production rate during TEST4 and TEST5 (recall Figure 2).

TEST4 and TEST5 included pulp sampling periods that had similar values in both production rate and motor load (recall Figure 2). For these periods, the values of measured pulp consistency differed only about $5 \%$ units while the differences in estimated consistency after the FZ reached $15 \%$ units (see Figure 4). As seen in Figure 6, significant differences in estimated total residence time were obtained. During TEST4, the plate gaps were considerably higher in both zones compared with TEST5. Estimated residence time for the samples in TEST2 showed that a lower plate gap resulted in a higher residence time. Therefore, it is not probable that the higher plate gaps in TEST4 explain the higher residence time obtained compared with TEST5.

It was found that the total residence time increased if any of the variables production rate, dilution water flow rate or plate gap was decreased. Considering residence time in the two different zones, the applied changes in production rate had most effect on the residence time in the $\mathrm{FZ}$ while the residence time in the $\mathrm{CD}$ zone was more affected by the changes in dilution water flow rate and plate gap, see Figure 7.

\section{Process variables and tensile index}

Measurements on handsheets made from the composite pulp samples gave a range in tensile index (TI) from about 24 to $36 \mathrm{Nm} / \mathrm{g}$. TI is shown with respect to specific energy 


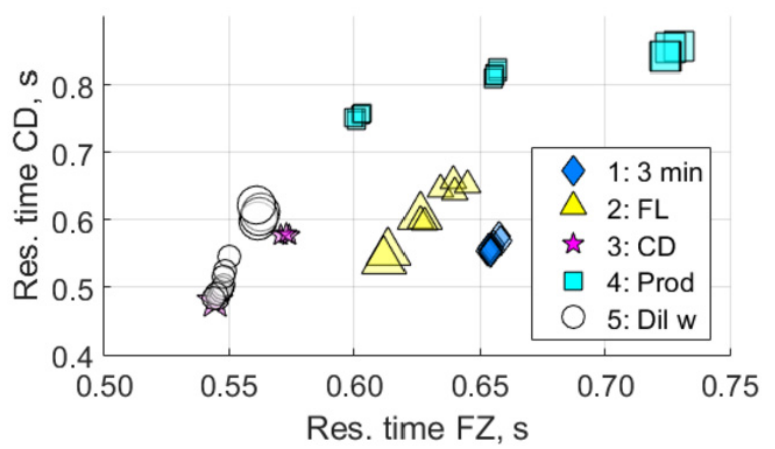

Figure 7: Residence time in the $C D$ zone versus residence time in the FZ. The residence time in the FZ was most affected by the changes in production rate (TEST4), while the residence time in the $\mathrm{CD}$ zone was more affected by the changes in dilution water flow rate and plate gap (TEST2 and 4).

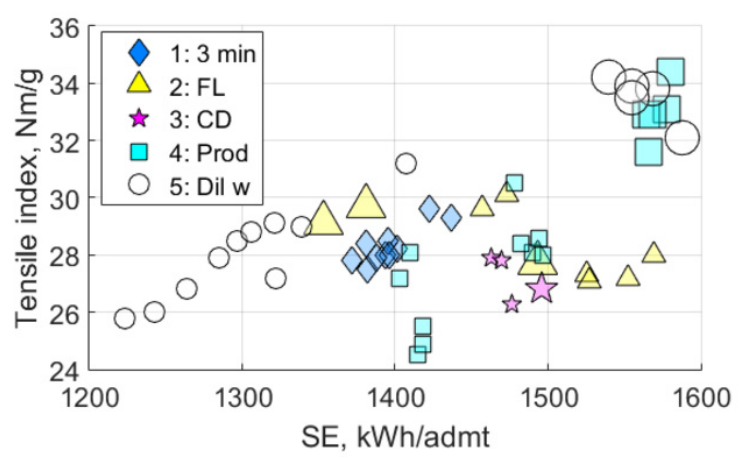

Figure 8: TI versus SE. The same tensile index value of $28 \mathrm{Nm} / \mathrm{g}$ was obtained with operating conditions for which the specific energy differed $300 \mathrm{kWh} / \mathrm{admt}$.

in Figure 8, and with respect to residence time in Figure 9. When considering all tests, there are no clear relations between TI and any of the two variables. For example, a TI value of $28 \mathrm{Nm} / \mathrm{g}$ was obtained for operation points, which differed as much as $300 \mathrm{kWh} / \mathrm{admt}$ in specific energy (Figure 8).

Tensile index clearly increased with residence time in TEST4 and 5 (Figure 9). However, the absolute values of estimated total residence time were much higher during test TEST4 than during TEST5. Comparison of the composite pulp sample periods that had similar values in both production rate and motor load (the arrows in the figures) shows that the lowest value in tensile index was obtained at the highest value of total residence time. For these selected composite pulp sampling periods, the values of measured blow line consistency were about the same, but the estimated values of pulp consistency after the FZ differed. The pulp consistency was highest in the selected sampling period from TEST4 and this probably relates to

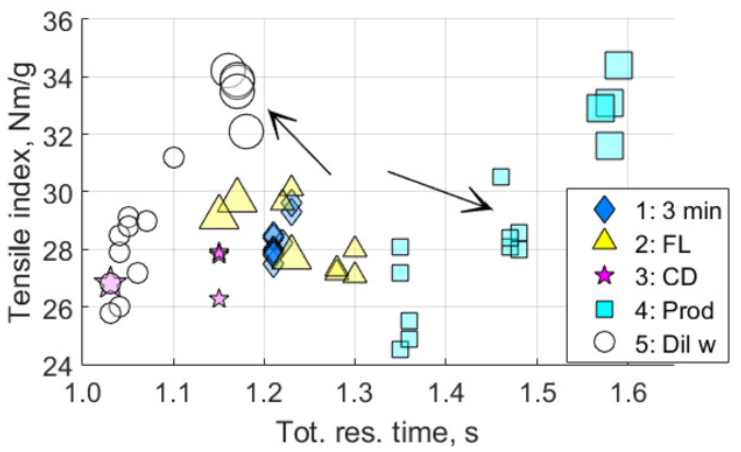

Figure 9: TI versus total residence time. In TEST4 and 5, positive correlations can be observed between the two variables. The residence time was, however, significantly higher during TEST4. The arrows indicate pulp sampling periods with similar values in both motor load and production rate.

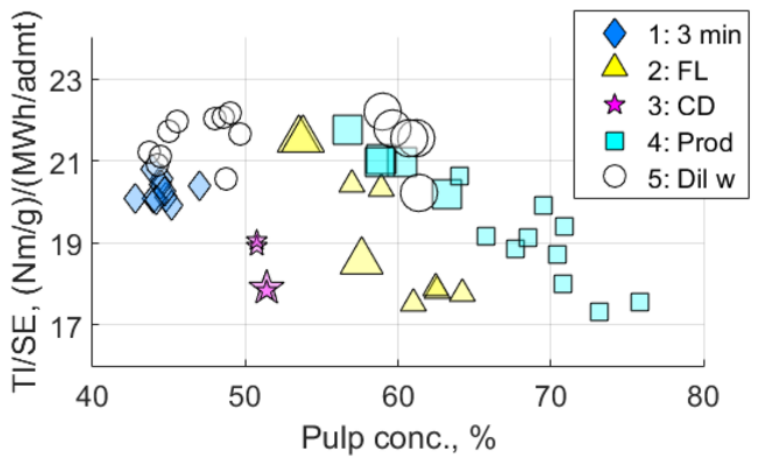

Figure 10: The ratio TI/SE seemed to have a maximum around a measured blow line pulp consistency of 50-55\%.

the higher values in total residence time and the lower values in TI.

For the ratio tensile index/specific energy (TI/SE) from all composite pulp samples from all five tests, a maximum is indicated at a blow line consistency of $50-55 \%$, see Figure 10. TEST3 is an exception, but the mentioned runnability problems motivate handling these values differently. If anything, they indicate that runnability problems could result in lower values in TI/SE.

For the selected composite pulp sample periods (with similar production rate and load) in TEST4, TI/SE values were around $19 \mathrm{Nm} / \mathrm{g}$, while in TEST5 it was around 21 $\mathrm{Nm} / \mathrm{g}$. As mentioned, in TEST4 both plate gaps were higher compared with TEST5, while the dilution water flow rate was higher in TEST5 (Table 4-5 in the appendix).

In our experience, $\mathrm{CD}$ refiners are known to be sensitive to changes in pulp consistency; increasing consistency is a common way to deliberately increase the specific energy. The latter is a strategy adopted from the com- 
mon belief that improved strength properties are obtained by increasing the specific energy. These tests show that a too high consistency might give lower values in TI/SE. This strategy is by no means generic, here this can be seen when comparing the selected periods for which the specific energy were similar, while the TI/SE clearly differed. This is probably related to the higher consistencies in TEST4, especially after the FZ (see Figure 1).

Analysing all composite pulp samples from all five tests, the obtained values for the TI/SE and the residence time give no clear indication of favourable operating conditions, Figure 11.

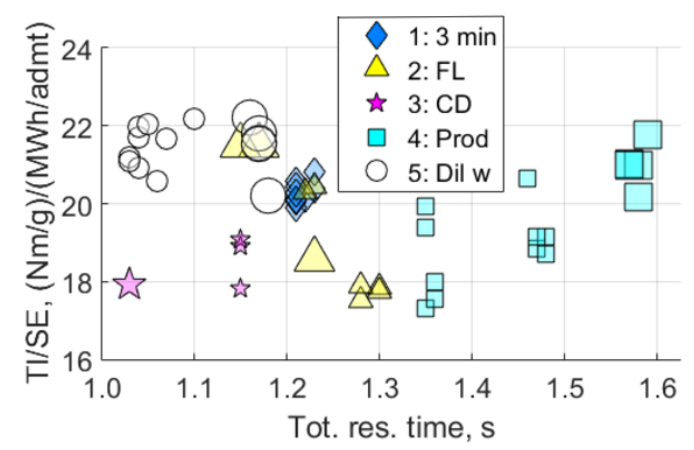

Figure 11: The ratio $\mathrm{TI} / \mathrm{SE}$ versus estimated residence time gave no specific indication of favourable operating conditions.

Between the selected sampling periods, about 0.3 seconds difference in residence time was obtained. For the TEST4 periods, the values were about $1.45 \mathrm{~s}$, while for the TEST5 periods, they were about $1.15 \mathrm{~s}$. In TEST2 a negative correlation between the TI/SE and total residence time was obtained, while in TEST4 this correlation is positive. For the periods of highest specific energy, over $1500 \mathrm{kWh} /$ admt seen in Figure 3, the highest FZ pulp consistency is obtained in TEST2, while TEST4-values were lower and the TEST5 values were even lower. This might be a reason for the decrease in TI/SE seen in Figure 10 during TEST4. For these periods, TEST4 and 5 had different settings in plate gaps and dilution water flow rates.

Taken together, the results from these tests suggest that if a high value of TI/SE is desired, it can be more important to maintain a certain pulp consistency in both FZ and $\mathrm{CD}$ than maintaining a certain residence time.

\section{Other pulp properties in relation to specific energy and tensile index}

Freeness, fibre length and Somerville shives decreased with increasing specific energy in each test. The slope of
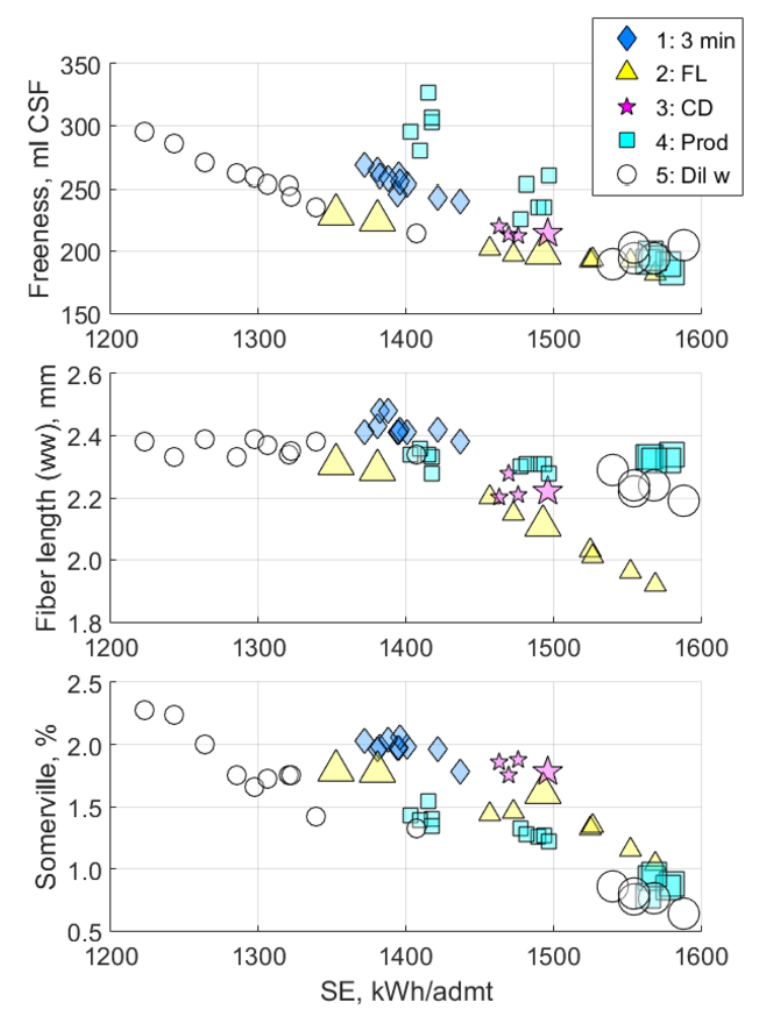

Figure 12: Freeness, fibre length and Somerville shives, all versus specific energy.

the relations varied slightly between the tests, see Figure 12. Composite pulp samples from TEST2 that had a low TI/SE ratio also had considerably lower weight-weighted average fibre length, compared to all the other composite pulp samples, for which the fibre length were similar.

In Figure 13, the pulp properties freeness, fibre length and Somerville shives are shown with respect to tensile index. As seen, considering all composite pulp samples from the five tests, there are no clear relations. Most striking is perhaps that the fibre length seems to be uncorrelated with tensile index. This is in line with the multivariate modelling results presented by Ferritsius (1996). In this work, it was found that fibre length and tensile index were separated by two independent factors, F1 and F2.

If TEST3 and parts of TEST2 are disregarded, it looks as if there is, as expected, a negative correlation between freeness and tensile index. These TEST 3 and TEST2 values, however, were obtained under clearly unfavourable operating conditions that undoubtedly should be avoided. As an example, Figure 13 shows that a pulp with a freeness of about $200 \mathrm{ml}$ can have tensile index in the large range 27-34 Nm/g. The pulps with a lower tensile index at given freeness also had a lower fibre length, especially the sam- 

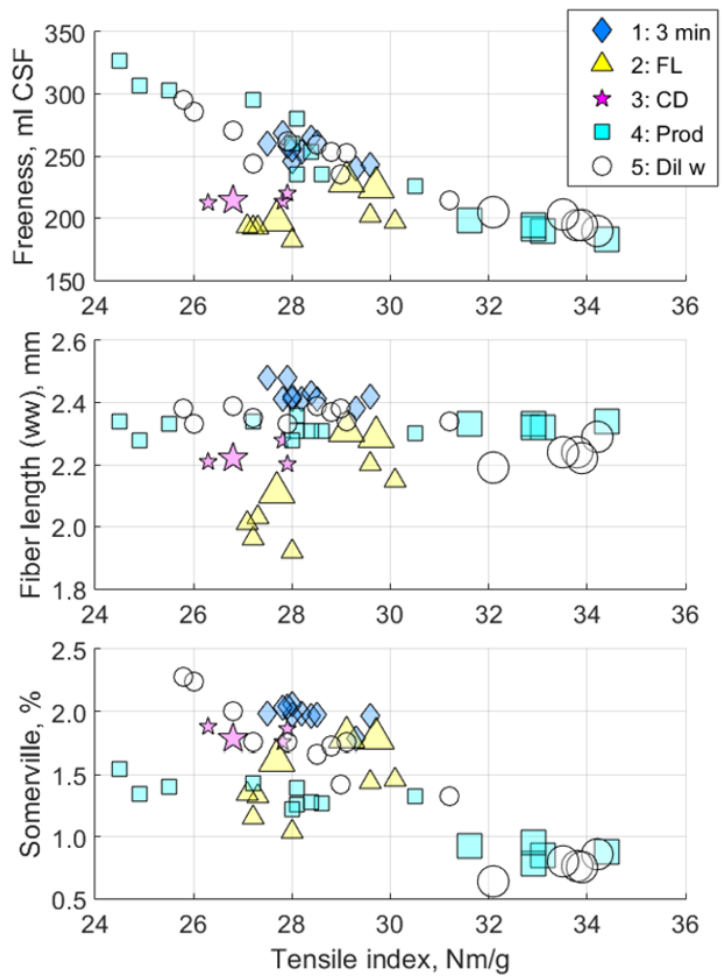

Figure 13: The variables freeness, fibre length and Somerville shives versus tensile index.

ples from TEST2. The shives content could also vary quite a lot at a given tensile index.

During continuous operation, online measurements of freeness, fibre length and shives are often used to characterize the pulp properties. These measurements are what in general is available and considered to be related to strength properties like tensile index. The results presented here, however, show that when relying on freeness there is an obvious risk of unfavourable operating conditions with respect to tensile index. Moreover, the values for freeness presented here are measured in a lab using composite pulp samples from the refiner blow line. An online analyser is typically located further downstream, which inevitably gives poorer measurements because of additional disturbances. The light scattering coefficient, unlike tensile index, increased with increased specific energy in the individual tests. However, between the tests, different values of the light scattering coefficient could be obtained at a given level of specific energy, see Table 3-7 in the appendix. For a certain value of tensile index, the light scattering coefficient could vary up to seven units, see Figure 14.

Fibrillation and cell wall thickness (CWT) is shown versus specific energy in Figure 15. Here, the specific en-

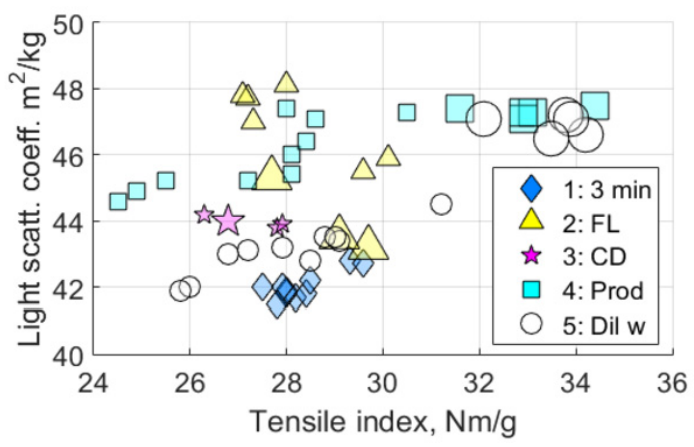

Figure 14: Light scattering coefficient versus tensile index.

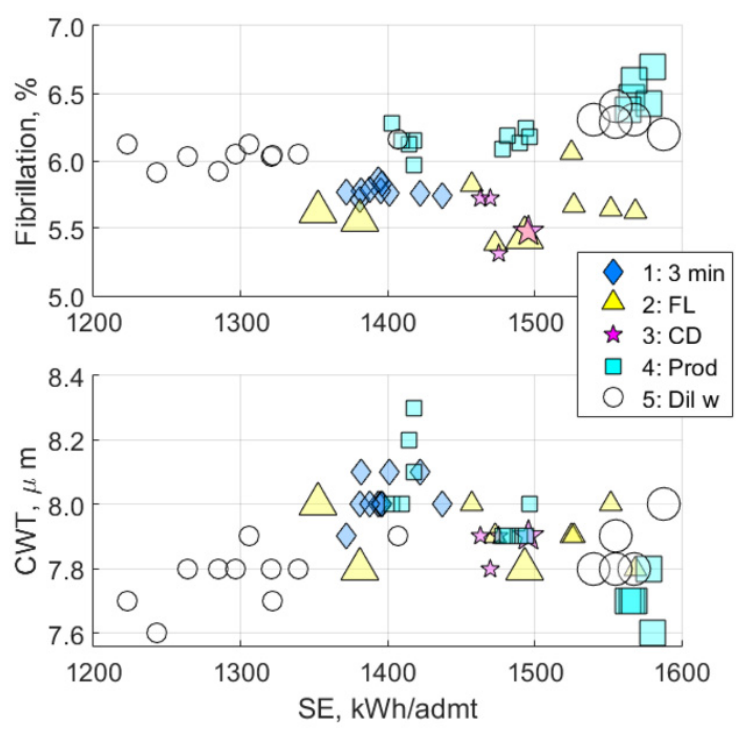

Figure 15: Fibrillation seems to be uncorrelated to specific energy. With increased specific energy, CWT decreased in TEST4, but increased slightly in TEST5.

ergy and fibrillation seemed uncorrelated. Cell wall thickness decreased with increased specific energy in TEST4, but seemed to increase slightly with increased specific energy in TEST5. As mentioned, the relations between pulp consistency and specific energy were also different for these two tests, (cf. Figure 3).

\section{Discussion}

An increase in pulp consistency has been recommended to maximize the strength properties of the pulp (Ettaleb et al. 2005). In this paper, it is shown that the pulp consistency can be too high and result in a decrease in the ratio $\mathrm{TI} / \mathrm{SE}$ when specific energy is increased. This suggests that it might be better to reduce the plate gaps than reduce the 
dilution water flow rates if the specific energy needs to be increased. This depends on the actual consistency profile. Continuous estimates of pulp consistencies could be delivered by the extended entropy model in combination with refining zone temperature sensors and provide a starting point for a process control strategy that can guarantee that such unfavourable operating conditions are avoided.

TEST1, 2, 4 and 5 could be summarized with respect to specific energy, tensile index and calculated consistency after both flat and CD zone, see Table 2. This shows that both TEST1 and TEST5 had process conditions where tensile index increased along with increased specific energy and increased consistency in both zones. In TEST2, tensile index was found to have a negative response with respect to specific energy and consistency in both zones.

Table 2: Values of selected measured and estimated variables during TEST1, 2, 4 and 5.

\begin{tabular}{|c|c|c|c|c|c|}
\hline Variable & & TEST1 & TEST2 & TEST4 & TEST5 \\
\hline \multirow{2}{*}{ SE [kWh/admt] } & Max & 1440 & 1580 & 1580 & 1590 \\
\hline & Min & 1370 & 1170 & 1400 & 1220 \\
\hline \multirow{2}{*}{ Est. ConsFZ [\%] } & Max & 62.0 & 90.0 & 77.5 & 62.0 \\
\hline & Min & 59.0 & 62.0 & 74.0 & 52.0 \\
\hline \multirow{2}{*}{ Est. ConsCD [\%] } & Max & 44.5 & 66.0 & 66.0 & 60.0 \\
\hline & Min & 47.5 & 47.0 & 57.5 & 44.0 \\
\hline \multirow{2}{*}{$\mathrm{TI}[\mathrm{Nm} / \mathrm{g}]$} & Max & 30.0 & 30.0 & 34.5 & 34.0 \\
\hline & Min & 26.8 & 25.5 & 24.5 & 26.0 \\
\hline \multirow{2}{*}{$\begin{array}{l}\text { TI/SE [(Nm/g)/ } \\
\text { (MWh/admt)] }\end{array}$} & Max & 20.8 & 21.4 & 21.8 & 22.2 \\
\hline & Min & 19.9 & 17.4 & 17.5 & 20.2 \\
\hline$\overline{\partial T I / \partial S E}$ & & $\uparrow$ & $\downarrow$ & $\uparrow$ & $\uparrow$ \\
\hline$\partial \mathrm{TI} / \partial$ ConsFZ & & $\uparrow$ & $\downarrow$ & $\downarrow$ & $\uparrow$ \\
\hline$\partial \mathrm{TI} / \partial$ ConsCD & & $\uparrow$ & $\downarrow$ & $\downarrow$ & $\uparrow$ \\
\hline
\end{tabular}

In TEST4, tensile index was found to increase with specific energy, but it decreased with pulp consistency. This is, considering these variables, an indication that the process was operated at conditions beyond optimal. This illustrates the nonlinear behaviour of the refining process. The process operating window should of course be chosen where tensile index is increased with increasing specific energy.

Decreasing the dilution water flow rate to the FZ had a considerably greater effect on the motor load than the corresponding decrease to the $\mathrm{CD}$ zone. Although the change in dilution water flow rate was made before the FZ, the influence on the calculated residence time was stronger in the CD zone than in the FZ. It is also very common that operators reduce the water to the flat zone when they need to improve the pulp properties and then increase the specific energy. This could result in lower tensile index, although specific energy is increased, which was shown in TEST2.
The ratio TI/SE has sometimes been referred to as energy efficiency (Ferritsius et al. 2014). This has been avoided in this paper since tensile index, although it is believed to be an important pulp property, is one of several pulp properties that could be of interest. Moreover, it is not likely that tensile index increases linearly with the specific energy all the way from zero to an attainable maximum for a given production unit. This paper analyses pulp from just one refiner and the differences in specific energy are rather modest. Comparing the ratio TI/SE with variables representing the process conditions, such as pulp consistency, should be a fair comparison.

In the literature, Strand et al. (1993) and Härkönen and Tienvieri (1995), for example, have shown that an increase in production rate can result in a lower specific energy while pulp properties are maintained. In this CD 82 refiner study, no such tendencies were found. This might depend on differences in segment types and ranges in pulp consistency. During the periods of higher production rates the pulp consistency values were also high, and this is believed to adversely affect the TI/SE. It would have been interesting to further explore the approach used in TEST4 and investigate if the operating conditions at each production rate could be optimized considering TI/SE.

Averages from fibre measurement in FiberLab such as fibrillation and cell wall thickness (CWT) have been studied and the values obtained were rather similar, although the variation was relatively large in both tensile index and specific energy. It might have been expected that an increase in tensile index should be followed by an increase in fibrillation or a decrease in CWT. Here, though, it was found that a certain tensile index value could correspond to a wide range in both fibrillation and CWT.

During TEST3, severe runnability problems were experienced. The refiner stopped during the test, a reduced number of composite pulp samples were obtained and the test was interrupted. These problems might explain the low values of the TI/SE obtained, but caution is needed, if interpreting any results from this test.

For each test, a high degree of co-variation between specific energy and estimated total residence time was found. The values of the residence time estimated in this study were slightly lower than those obtained in the experimental study conducted by Härkönen et al. (1999). Both methods have their limitations and uncertainties. As an example, the extended entropy model does not account for any re-circulation of pulp prior to the pressure maximum. Still, the results are within the same range and thereby support each other. Although there was a high degree of co-variation between estimated residence time (from the extended entropy model) and specific energy within each 
test, this was not the case when considering all tests. Unlike the changes in the plate gap and the dilution water flow rate, the changes in the production rate had more influence on the residence time in the FZ than in the $\mathrm{CD}$ zone.

Taken together the results from these tests suggest that if the aim is a high value of TI/SE, it might be more important to maintain a certain pulp consistency in both FZ and $\mathrm{CD}$ than maintaining a certain residence time. The results associated with estimated pulp consistencies were easier to interpret compared with results for residence times, implying that additional tests are required for the latter variable.

\section{Conclusions}

Process variables and pulp properties have been studied for a CD 82 refiner when running at different operating points. Results from five tests have been compared and the following was found:

In these tests, the ratio TI/SE had a maximum at about $55 \%$ measured blow line consistency. Unfavourable operating conditions were identified at high pulp consistencies, especially after the FZ, where pulp consistencies above $70 \%$ were observed. The estimated pulp consis- tency after FZ could be very different, while the measured pulp consistency after blow line was similar. It is therefore important to have access to information about the refining zone conditions when searching for an operation point in terms of the ratio tensile index/specific energy (TI/SE).

Freeness, fibre length and shives (which are possible to measure on-line) are considered related to strength properties such as tensile index. In this study, however, no clear-cut relations were found. Freeness, Somerville shives and light scattering coefficient exhibited a high degree of co-variation with specific energy in the individual tests, but when all tests are considered, the results appear rather scattered.

Funding: This publication is part of the Energy Efficient Mechanical Pulping (e2mp) program at Mid Sweden University funded by the Knowledge Foundation, Stora Enso, SCA, Holmen, and Valmet. Special thanks to all who gave support to these trials and testing of the pulps.

Conflict of interest statement: The authors do not have any conflicts of interest to declare.

\section{Appendix}

Table 3: Test 1.

\begin{tabular}{|c|c|c|c|c|c|c|c|c|c|c|}
\hline Composite Pulp Sample & 1 & 2 & 3 & 4 & 5 & 6 & 7 & 8 & 9 & 10 \\
\hline Load, MW & 19.2 & 18.7 & 18.5 & 19.0 & 18.5 & 18.6 & 18.7 & 18.7 & 18.5 & 18.3 \\
\hline Gap FZ, mm & 1.53 & 1.53 & 1.54 & 1.49 & 1.53 & 1.54 & 1.53 & 1.53 & 1.55 & 1.57 \\
\hline Gap CD, mm & 0.86 & 0.85 & 0.87 & 0.85 & 0.85 & 0.85 & 0.86 & 0.85 & 0.85 & 0.86 \\
\hline Dil. water FZ, l/s & 3.26 & 3.25 & 3.27 & 3.25 & 3.26 & 3.27 & 3.26 & 3.27 & 3.26 & 3.26 \\
\hline Dil. water CD, I/s & 4.76 & 4.76 & 4.76 & 4.76 & 4.76 & 4.76 & 4.76 & 4.76 & 4.76 & 4.76 \\
\hline Prod., admt/h & 13.4 & 13.4 & 13.4 & 13.4 & 13.4 & 13.4 & 13.4 & 13.4 & 13.4 & 13.4 \\
\hline SE., kWh/admt & 1437 & 1401 & 1381 & 1422 & 1382 & 1394 & 1395 & 1396 & 1388 & 1372 \\
\hline Calc. conc. FZ, \% & 60.7 & 59.5 & 59.0 & 60.9 & 59.1 & 59.4 & 59.3 & 59.1 & 59.0 & 58.7 \\
\hline Calc. conc. CD, \% & 47.2 & 46.1 & 45.3 & 46.7 & 45.3 & 45.6 & 45.7 & 45.8 & 45.4 & 45.0 \\
\hline Tot. res. time, s & 1.23 & 1.22 & 1.21 & 1.23 & 1.21 & 1.21 & 1.21 & 1.21 & 1.21 & 1.21 \\
\hline Res. time ratio FZ/CD & 1.14 & 1.16 & 1.18 & 1.16 & 1.18 & 1.17 & 1.17 & 1.17 & 1.18 & 1.19 \\
\hline Force FZ 3, N & 1.15 & 1.16 & 1.16 & 1.14 & 1.16 & 1.14 & 1.17 & 1.15 & 1.16 & 1.14 \\
\hline Pulp conc., \% & 47.0 & 44.8 & 44.5 & 43.9 & 45.2 & 44.0 & 44.4 & 44.2 & 42.8 & 44.7 \\
\hline Freeness, ml CSF & 240 & 253 & 265 & 243 & 260 & 246 & 261 & 255 & 258 & 269 \\
\hline Fiber length (ww), mm & 2.38 & 2.41 & 2.43 & 2.42 & 2.48 & 2.41 & 2.41 & 2.42 & 2.48 & 2.41 \\
\hline CWT, $\hat{\imath} 1 / 4 \mathrm{~m}$ & 8.0 & 8.1 & 8.0 & 8.1 & 8.1 & 8.0 & 8.0 & 8.0 & 8.0 & 7.9 \\
\hline Fibrillation, \% & 5.74 & 5.76 & 5.71 & 5.76 & 5.78 & 5.86 & 5.78 & 5.83 & 5.79 & 5.77 \\
\hline Curl, \% & 13.7 & 13.5 & 13.6 & 13.8 & 13.7 & 13.8 & 13.8 & 13.7 & 13.8 & 13.8 \\
\hline Somerville, \% & 1.78 & 1.98 & 1.96 & 1.96 & 1.98 & 1.97 & 1.97 & 2.06 & 2.04 & 2.03 \\
\hline Density, $\mathrm{kg} / \mathrm{m}^{3}$ & 319 & 313 & 317 & 325 & 321 & 320 & 321 & 324 & 323 & 325 \\
\hline Tensile index, Nm/g & 29.3 & 28.2 & 28.4 & 29.6 & 27.5 & 28.0 & 28.5 & 28.0 & 27.9 & 27.8 \\
\hline Elongation, \% & 1.83 & 1.77 & 1.78 & 1.81 & 1.69 & 1.71 & 1.74 & 1.71 & 1.70 & 1.76 \\
\hline Tear index, $\mathrm{mNm}^{2} / \mathrm{g}$ & 7.02 & 6.90 & 7.06 & 7.09 & 7.26 & 7.10 & 7.27 & 7.19 & 7.20 & 6.90 \\
\hline Light scatt. coeff. $\mathrm{m}^{2} / \mathrm{kg}$ & 42.8 & 41.7 & 41.8 & 42.7 & 42.0 & 41.8 & 42.2 & 41.9 & 42.0 & 41.5 \\
\hline
\end{tabular}


Table 4: Test 2.

\begin{tabular}{lrrrrrrrrr}
\hline Composite Pulp Sample & $\mathbf{2 1}$ & $\mathbf{2 2}$ & $\mathbf{2 3}$ & $\mathbf{2 4}$ & $\mathbf{2 5}$ & $\mathbf{2 6}$ & $\mathbf{2 7}$ & $\mathbf{2 8}$ & $\mathbf{2 9}$ \\
\hline Load, MW & 23.7 & 24.6 & 24.9 & 23.3 & 21.9 & 23.1 & 24.2 & 24.2 & 21.4 \\
Gap FZ, mm & 1.35 & 1.20 & 1.05 & 1.21 & 1.37 & 1.35 & 1.36 & 1.35 & 1.36 \\
Gap CD, mm & 0.78 & 0.79 & 0.78 & 0.77 & 0.77 & 0.79 & 0.78 & 0.75 & 0.78 \\
Dil. water FZ, l/s & 3.42 & 3.43 & 3.43 & 3.43 & 3.43 & 3.36 & 3.26 & 3.17 & 3.43 \\
Dil. water CD, l/s & 5.23 & 5.24 & 5.24 & 5.23 & 5.23 & 5.23 & 5.23 & 5.24 & 5.23 \\
Prod., admt/h & 15.9 & 15.9 & 15.9 & 15.9 & 15.9 & 15.9 & 15.9 & 15.9 & 15.9 \\
SE., kWh/admt & 1493 & 1552 & 1569 & 1473 & 1381 & 1457 & 1525 & 1527 & 1353 \\
Calc. conc. FZ, \% & 76.7 & 84.3 & 89.8 & 77.9 & 69.3 & 75.9 & 81.0 & 82.0 & 68.2 \\
Calc. conc. CD, \% & 60.0 & 64.1 & 65.4 & 58.9 & 53.7 & 58.6 & 64.0 & 65.3 & 52.3 \\
Tot. res. time, s & 1.23 & 1.28 & 1.30 & 1.23 & 1.17 & 1.22 & 1.28 & 1.30 & 1.15 \\
Res. time ratio FZ/CD & 1.03 & 0.98 & 0.97 & 1.04 & 1.11 & 1.05 & 1.00 & 0.99 & 1.13 \\
Force FZ 3, N & 1.11 & 1.20 & 1.26 & 1.19 & 1.21 & 1.15 & 1.11 & 1.13 & 1.26 \\
Pulp conc., \% & 57.6 & 61.0 & 62.6 & 57.0 & 53.5 & 58.9 & 62.5 & 64.2 & 53.8 \\
Freeness, ml CSF & 198 & 192 & 182 & 197 & 225 & 202 & 192 & 193 & 230 \\
Fiber length (ww), mm & 2.11 & 1.96 & 1.92 & 2.15 & 2.29 & 2.20 & 2.03 & 2.01 & 2.31 \\
CWT, î1/4m & 7.8 & 8.0 & 7.8 & 7.9 & 7.8 & 8.0 & 7.9 & 7.9 & 8.0 \\
Fibrillation, \% & 5.43 & 5.64 & 5.62 & 5.39 & 5.56 & 5.82 & 6.06 & 5.67 & 5.62 \\
Curl, \% & 14.1 & 13.6 & 13.5 & 13.6 & 13.6 & 13.9 & 13.8 & 13.4 & 13.6 \\
Somerville, \% & 1.61 & 1.15 & 1.04 & 1.46 & 1.78 & 1.44 & 1.32 & 1.34 & 1.79 \\
Density, kg/m ${ }^{3}$ & 329 & 352 & 362 & 343 & 330 & 343 & 348 & 358 & 326 \\
Tensile index, Nm/g & 27.7 & 27.2 & 28.0 & 30.1 & 29.7 & 29.6 & 27.3 & 27.1 & 29.1 \\
Elongation, \% & 1.78 & 1.71 & 1.73 & 1.82 & 1.73 & 1.79 & 1.78 & 1.73 & 1.83 \\
Tear index, mNm ${ }^{2} / \mathrm{g}$ & 6.37 & 5.72 & 5.86 & 6.72 & 7.21 & 6.88 & 5.95 & 6.11 & 7.27 \\
Light scatt. coeff. m ${ }^{2} / \mathrm{kg}$ & 45.3 & 47.7 & 48.1 & 45.9 & 43.2 & 45.5 & 47.0 & 47.8 & 43.5 \\
\hline & & & & & & & & &
\end{tabular}

Table 5: Test 3.

\begin{tabular}{lrrrr}
\hline Composite Pulp Sample & $\mathbf{3 1}$ & $\mathbf{3 2}$ & $\mathbf{3 3}$ & $\mathbf{3 4}$ \\
\hline Load, MW & 22.4 & 22.1 & 22.1 & 21.9 \\
Gap FZ, mm & 1.23 & 1.24 & 1.22 & 1.23 \\
Gap CD, mm & 0.63 & 0.57 & 0.63 & 0.64 \\
Dil. water FZ, l/s & 3.78 & 3.79 & 3.78 & 3.79 \\
Dil. water CD, l/s & 5.12 & 5.11 & 5.12 & 5.06 \\
Prod., admt/h & 15.0 & 15.0 & 15.0 & 15.0 \\
SE., kWh/admt & 1496 & 1476 & 1470 & 1463 \\
Calc. conc. FZ, \% & 60.7 & 58.0 & 59.8 & 59.5 \\
Calc. conc. CD, \% & 50.6 & 49.6 & 49.4 & 49.5 \\
Tot. res. time, s & 1.03 & 1.15 & 1.15 & 1.15 \\
Res. time ratio FZ/CD & 1.13 & 0.99 & 0.99 & 0.99 \\
Force FZ 3, N & 1.23 & 1.28 & 1.27 & 1.25 \\
Pulp conc., \% & 51.4 & 51.4 & 50.8 & 50.8 \\
Freeness, ml CSF & 214 & 212 & 213 & 220 \\
Fiber length (ww), mm & 2.22 & 2.21 & 2.28 & 2.20 \\
CWT, Î1/4m & 7.9 & 7.9 & 7.8 & 7.9 \\
Fibrillation, \% & 5.48 & 5.31 & 5.72 & 5.72 \\
Curl, \% & 14.5 & 13.7 & 14.8 & 14.0 \\
Somerville, \% & 1.78 & 1.88 & 1.75 & 1.86 \\
Density, kg/m ${ }^{3}$ & 316 & 328 & 337 & 340 \\
Tensile index, Nm/g & 26.8 & 26.3 & 27.8 & 27.9 \\
Elongation, \% & 1.78 & 1.71 & 1.77 & 1.78 \\
Tear index, mNm ${ }^{2} / \mathrm{g}$ & 6.42 & 6.36 & 6.82 & 6.79 \\
Light scatt. coeff. m ${ }^{2} / \mathrm{kg}$ & 44.0 & 44.2 & 43.8 & 43.9 \\
\hline & & & &
\end{tabular}


Table 6: Test 4.

\begin{tabular}{|c|c|c|c|c|c|c|c|c|c|c|c|c|c|c|c|}
\hline Composite Pulp & 35 & 36 & 37 & 38 & 39 & 40 & 41 & 42 & 43 & 44 & 45 & 46 & 47 & 48 & 49 \\
\hline & 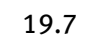 & .0 & 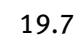 & 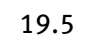 & .0 & . & נ. & 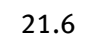 & 1.5 & 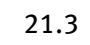 & 2.3 & & & 2.4 & 22 \\
\hline & 8 & 48 & 18 & & 48 & 48 & 47 & & .48 & 48 & .49 & .48 & 1.48 & .48 & $1.4 \varepsilon$ \\
\hline ap $C D, m m$ & 14 & 1.14 & 1.13 & .13 & .14 & 15 & .15 & .15 & 1.15 & 1.14 & .11 & 1.12 & 1.14 & .14 & 1.13 \\
\hline & 39 & 3.39 & 3.39 & 3 & 3.40 & 3.41 & 3.40 & .40 & 3.39 & 3.39 & 3.38 & 3.41 & 3.40 & .43 & 3.3 \\
\hline & .89 & 3.88 & 3.88 & 3.88 & 3.88 & 3.88 & 3.88 & 3.88 & 3.88 & 3.89 & 3.88 & 3.89 & 3.88 & .89 & 3.8 \\
\hline & 2.5 & 12.5 & 12.5 & 12.5 & 12.5 & 14.4 & 14.4 & 14.4 & 14.4 & 14.4 & 5.9 & & 5.9 & 5.9 & 15 \\
\hline & 1580 & 1566 & 1578 & 1564 & 1568 & 1490 & 1494 & 1497 & 1478 & 1482 & 1418 & 1415 & 1403 & 1410 & 141 \\
\hline$\%$ & 5.5 & 75.0 & 75.0 & 74.1 & 74.2 & 76.0 & 76.4 & 76.5 & 75.2 & 75.6 & 76.6 & 76.2 & 5.8 & 5.6 & 77 \\
\hline$\%$ & - & 58.6 & 8.6 & 57.6 & 57.7 & 64.5 & 64.9 & 65.2 & 63.9 & 64.2 & 65.9 & 65.4 & 65.0 & 5.3 & 66 \\
\hline t. & 59 & 1.58 & 58 & 1.57 & 1.57 & 1.47 & 1.48 & 1.48 & 1.46 & 1.47 & 1.36 & 1.35 & 5 & .35 & 1.3 \\
\hline & 85 & 0.85 & .85 & 0.86 & 0.86 & 0.80 & 0.80 & 0.80 & 0.81 & 0.81 & 0.80 & 0.80 & 0.80 & .80 & 0.8 \\
\hline rc & 56 & 0.55 & 0.56 & 0.5 & 0.58 & 0.79 & 0.78 & 0 & 0.78 & 0.79 & 0.99 & & & 99 & 0.9 \\
\hline ال & & 63.2 & 60.3 & 58.9 & 58.8 & 67.7 & 68.5 & 70.4 & 64.0 & 65.8 & 70.8 & .2 & .9 & .5 & 75 \\
\hline & & 198 & 0 & & 194 & 235 & 235 & & 226 & 253 & 303 & 327 & & 30 & 30 \\
\hline & 2.34 & 2.33 & 2.32 & 2.3 & 2.32 & 2.31 & 2.31 & 2.28 & 2.30 & 2.31 & 2.33 & 2.34 & 2.34 & 2.36 & 2.2 \\
\hline & 7.6 & 7.7 & 7.8 & & 7.7 & 7.9 & 7.9 & & & 7.9 & 8.1 & & 8.0 & 8.0 & \\
\hline 1 & & 6.47 & 6.42 & & 6.6 & 6.13 & 6.24 & & 6.09 & 6.19 & 6.15 & 2 & 6.28 & 5 & 5.9 \\
\hline lat & 15.3 & 15.1 & 15.1 & 14.9 & 15.4 & 14.4 & 14.6 & 14.5 & 14.6 & 14.6 & 14.6 & 14.6 & 15.0 & 4.8 & 14.2 \\
\hline omervi & 0.88 & 0.92 & 0.85 & 0.78 & 0.95 & 1.26 & 1.27 & 1.22 & 1.32 & 1.28 & 1.40 & 1.54 & 1.43 & 1.39 & 1.3 \\
\hline ensity & & 355 & & & 364 & 341 & & & 356 & 346 & 336 & 337 & 339 & 350 & 33 \\
\hline & 34.4 & 31.6 & 33.1 & 32.9 & 32.9 & 28.1 & 28.6 & 28.0 & 30.5 & 28.4 & 25.5 & 24.5 & 27.2 & 8.1 & 24. \\
\hline & 1.92 & 1.83 & 1.86 & 1.91 & 1.88 & 1.75 & 1.66 & 1.67 & 1.71 & 1.69 & 1.53 & 1.56 & 1.63 & 1.68 & 1.5 \\
\hline Tear & 7.47 & 7.22 & 7.59 & 7.31 & 7.37 & 7.16 & 6.95 & 6.48 & 6.93 & 6.61 & 6.19 & 6.23 & 6.55 & 6.83 & 6.06 \\
\hline Light scatt. coeff. $\mathrm{m}^{2} / \mathrm{kg}$ & 47.5 & 47.4 & 47.3 & 47.1 & 47.3 & 46.0 & 47.1 & 47.4 & 47.3 & 46.4 & 45.2 & 44.6 & 45.2 & 45.4 & 44. \\
\hline
\end{tabular}

Table 7: Test 5.

\begin{tabular}{|c|c|c|c|c|c|c|c|c|c|c|c|c|c|c|c|}
\hline Comp & 50 & 51 & 52 & 53 & 54 & 55 & 56 & 57 & 58 & 59 & 60 & 61 & 62 & 63 & 6 \\
\hline & 21.9 & 3 & 22.1 & 22.1 & & 4 & 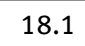 & & & & & & & & \\
\hline ap FZ & 0 & 07 & 86 & 0.86 & .87 & & .85 & 0.86 & & & .85 & .86 & 0.85 & .85 & 0.86 \\
\hline ap & 67 & 0.67 & 0.67 & 0.67 & .65 & 0.65 & 0.64 & .65 & 0.65 & 0.65 & .67 & .66 & 0.66 & .65 & 0.6 \\
\hline 7 & 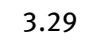 & 3.28 & 3.28 & 3.28 & & 3.5 & 3.51 & 3.51 & & 3.51 & & 1 & 3 & .51 & 3.5 \\
\hline 1. voat & .69 & 4.70 & 4.70 & 4.69 & 4.70 & 4.69 & 4.69 & 4.69 & 4.69 & 4.69 & 5 & 4.44 & 4.45 & .44 & 4.4 \\
\hline od., a & 4.2 & \pm & 14.2 & 14.2 & 14.2 & 14.3 & 14.3 & 14.3 & 14.3 & 14.3 & .2 & 14.2 & 14.2 & 4.2 & 14.2 \\
\hline 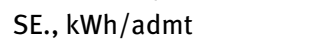 & 540 & 1568 & 1555 & 1555 & 1588 & 1285 & 1264 & 1297 & 1321 & 1306 & 1407 & 1339 & 1322 & 1243 & 122 \\
\hline & & & .1 & & & 3.4 & 2.9 & 6 & 4.3 & 3.9 & & .6 & 2 & .4 & - \\
\hline alc & 7.7 & 59.2 & 58.4 & 5 & 60.4 & 45.4 & 44.7 & 45 & 46.8 & 46.2 & 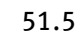 & 48.8 & 48.1 & .2 & 44. \\
\hline & & 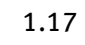 & 17 & & & 1.04 & 3 & 1 & 05 & 05 & 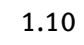 & 7 & 1. & 04 & 1.0 \\
\hline & 94 & 2 & 93 & 0 & 0 & 1.11 & 1 & 1 & 1.09 & 0 & 1 & 1. & 1. & 1 & 1.1 \\
\hline & & 4 & 62 & 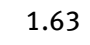 & 1.68 & 1.28 & 1 & 1.3 & 1 & 1.31 & 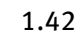 & 1.29 & 1. & 25 & 1.2 \\
\hline & 9.0 & 61.2 & 59.6 & 60.7 & 61.4 & 45.0 & 43.7 & 45.5 & 48.0 & 48.6 & 49 & 49.7 & 48.7 & 4.3 & 44. \\
\hline ee & & & 194 & & & 262 & 270 & & 2 & 253 & & & 2 & 286 & 29 \\
\hline he & .29 & 2.24 & 2.22 & 2.24 & 2.19 & 2.33 & 2.39 & 2.39 & 2.34 & 2.37 & 2.34 & 2.38 & 2.35 & 2.33 & 2.38 \\
\hline & & 7. & 7.9 & & 8.0 & 7.8 & 7.8 & 7. & & 7.9 & 7.9 & & & 7.6 & 7.7 \\
\hline bril & 3 & 6.3 & 6.4 & 6.29 & 6.2 & 5.92 & 6.03 & 6.05 & 6.03 & 6.12 & .16 & 6.05 & 6.04 & .91 & 6.12 \\
\hline & & & 14.5 & & 14.4 & & & & & & & & 14.1 & .8 & 13.9 \\
\hline & 0.86 & 0.76 & 0.75 & 0.80 & 0.64 & 1.75 & 2.00 & 1.66 & 1.75 & 1.72 & 1.32 & 1.42 & 1.75 & 2.24 & 2.2 \\
\hline$/ \mathrm{m}^{3}$ & & & 376 & & & 333 & & & 340 & & 348 & 333 & 329 & 331 & 327 \\
\hline & 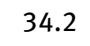 & 33.8 & 33.9 & 33.5 & 32.1 & 27.9 & 26.8 & 28.5 & 29.1 & 28.8 & 31.2 & 29.0 & 27.2 & 26.0 & 25.8 \\
\hline & 1.80 & 1.83 & 1.81 & 1.91 & 1.82 & 1.76 & 1.71 & 1.76 & 1.81 & 1.76 & 1.85 & 1.78 & 1.78 & 1.68 & 1.75 \\
\hline Tear index, $\mathrm{mNr}$ & 7.44 & 7.51 & 7.74 & 7.54 & 7.12 & 7.18 & 6.88 & 7.16 & 7.14 & 7.10 & 7.35 & 7.26 & 6.92 & 6.75 & 6.44 \\
\hline Light scatt. coeff. $\mathrm{m}^{2} / \mathrm{k}$ & 46.6 & 47.2 & 47.1 & 46.5 & 47.1 & 43.2 & 43.0 & 42.8 & 43.4 & 43.5 & 44.5 & 43.5 & 43.1 & 42.0 & 41.9 \\
\hline
\end{tabular}




\section{References}

Backlund, H.-O. (2004) Measurement of shear force, temperature profiles and fibre development in mill-scale TMP refiners. Licentiate thesis, Mid Sweden University ISBN 91-87908-81-6.

Bussiere, S., Vuorio, P., Ullmar, M., Hensley, E., Arid, J., Huhtanen, J.-P. (2007) Mill scale development towards high-production, low-energy TMP refining line. In: Prceedings, Int. Mech. Pulping Conf., Minneapolis, USA.

Deer, G., Carello, G., Fox, B., Cloutier, D. (2005) Power cost reduction through advanced quality control and refiner segment change at Tembec Pine Falls. In: Prceedings, Int. Mech. Pulping Conf., Minneapolis, USA.

Engstrand, P., Engberg, B., Eds. (2014) Filling the Gap - Final report. Report series FSCN 2014:57, Mid-Sweden University, Sundsvall, Sweden, ISSN 1650-5387.

Ettaleb, L., Roche, A.A., Miles, K. (2005) Method of refining wood chips or pulp in a high consistency conical disc refiner. Patent number: US7240863 B2.

Ferritsius, O. (1996) Control of fundamental pulp properties in TMP and SGW production by the use of factor analysis. In: SPCI, Stockholm, Sweden.

Ferritsius, R., Ferritsius, O., Hill, J., Karlström, A., Eriksson, K. (2018) TMP properties and process conditions in a CD82 chip refiner at different operation points Part I: Step changes of the process variables, description of the separate tests. Nord. Pulp Pap. Res. J. accepted.

Ferritsius, R., Ferritsius, O., Hill, J., Karlström, A., Ferritsius, J. (2017) Process considerations and its demands on TMP property measurements - A study on tensile index. Nord. Pulp Pap. Res. J. 32(1):45-53.

Ferritsius, R., Hill, J., Ferritsius, O., Karlström, A. (2014) On energy efficiency in chip refining. In: Proceedings, Int. Mech. Pulping Conf., Helsinki, Finland.

Ferritsius, O., Jämte, J., Ferritsius, R.: (1989) Single and double disc refining at Stora Kvarnsveden. In: Prceedings, Int. Mech. Pulp. Conf., Helsinki, Finland, pp. 58-71.

Fostokjian, R., Arid, J., Vuorio, P., Huhtanen, J.-P. (2005) Development results in reducing of refining energy consumption at Tempec paper group - Spruce Falls operations. In: Int. Mech. Pulping Conf., Oslo, Norway.

Härkönen, E., Huusari, E., Ravila, P. (1999) Residence time of fiber in a single disc refiner. In: Proceedings, Int. Mech. Pulping Conf., Huston, USA.

Härkönen, E., Tienvieri, T. (1995) The influence of production rate on refining in a specific refiner. In: Int. Mech. Pulping Conf., Ottawa, Canada.
Hill, J. (1993) Process understanding profits from sensor and control developments. In: Int. Mech. Pulping Conf.

Hill, J., Saarinen, K., Stenros, R. (1993) On the control of chip refining systems. Pulp Pap. Can. 94(6):43-47.

Johansson, O., Hogan, D., Blankenship, D., Snow, E., More, W., Qualls, R., Pugh, K., Wonderer, M. (2001) Improved process optimization through adjustable refiner plates. In: Proceedings, Int. Mech. Pulping Conf., Helsinki, Finland.

Johansson, B.-L., Karlsson, H., Jung, E. (1980) Experiences with computer control, based on optical sensors for pulp quality, of a two-stage TMP-plant. In: Proceedings, Process Control Conf., Halifax, Nova Scotia, Canada.

Johansson, O., Richardson, J. (2005) The effect of refining zone temperature on refining efficiency and pulp quality. In: Proceedings, Int. Mech. Pulping Conf., Oslo, Norway.

Karlström, A., Eriksson, K. (2014) Fiber energy efficiency Part I-IV. Nord. Pulp Pap. Res. J. 29(2):322-331, 332-343, and 29(3):401-408, 409-417.

Karlström, A., Hill, J., Ferritsius, R., Ferritsius, O. (2015) Pulp property development Part I: Interlacing undersampled pulp properties and TMP process data using piece-wise linear functions. Nord. Pulp Pap. Res. J. 30(4):599-608.

Karlström, A., Hill, J., Ferritsius, R., Ferritsius, O. (2016a) Pulp property development Part II: Process nonlinearities and its influence on pulp property development. Nord. Pulp Pap. Res. J. 31(2):287-299.

Karlström, A., Hill, J., Ferritsius, R., Ferritsius, O. (2016b) Pulp property development Part III: Fiber residence time and consistency profile impact on specific energy and pulp properties. Nord. Pulp Pap. Res. J. 31(2):300-307.

Karlström, A., Isaksson, A. (2009) Multi-rate optimal control of TMP refining processes. In: Proceedings, Int. Mech. Pulping Conf., Sundsvall, Sweden.

Miles, K.B., May, W.D. (1989) The flow of pulp in chip refiners. In: Int. Mech. Pulping Conf., Helsinki, Finland, Tappi, Peachtree Corners, GA, USA.

Strand, B.C., Mokvist, A., Falk, B., Jackson, M. (1993) The effect of production rate on specific energy consumption in high consistency chip refining. In: Proceedings, Int. Mech. Pulping Conf., Oslo, Norway.

Tistad, G., Asklund, S., Görfelt, P. (1981) TMP for newsprint produced by single stage refining with and without conical periphery segments. Operating experience from Hallsta Paper mill. In: Proceedings, Int. Mech. Pulping Conf., Oslo, Norway.

Vikman, K., Vuorio, P., Huhtanen, J.-P., Huhtokari, J. (2005) Residence time measurements for a mill scale high consistency CD refiner line. In: Proceedings, Int. Mech. Pulping Conf., Oslo, Norway. 